\title{
Management of a Patient with Traumatic Tetraplegia from Central Australia: Case Report
}

\author{
A. Winsor, MBBS, ${ }^{1}$ R. Marshall, MBBS, DPRM, FACRM, ${ }^{2}$ R. D. \\ Fraser, MBBS, FRACS ${ }^{3}$ \\ ${ }^{1}$ Rehabilitation Registrar, ${ }^{2}$ Director of Spinal Injuries Rehabilitation, ${ }^{3}$ Director of \\ Spinal Injuries Unit, Department of Orthopaedic Surgery and Trauma, Royal \\ Adelaide Hospital, North Terrace, Adelaide, South Australia.
}

\begin{abstract}
Summary
During the 6-year period up to 1 fanuary 1988, 10 patients were admitted to our unit from Central Australia with spinal cord injuries resulting from motor vehicle accidents. Of these half had received their injury whilst resting unrestrained in the rear of a moving vehicle. Three of these were recumbent.

The case is presented of a 26-year-old male who was injured whilst resting in the rear of a moving vehicle that left the roadway and rolled in remote central Australia. The injuries sustained were a closed head injury, fractures of the left lateral masses of C5, C6 and C7, a burst fracture of $C 7$ with an asymmetrical complete tetraplegia: $C 5$ on the left, C6 on the right.

Initial orthopaedic management was skeletal traction. An inpatient rehabilitation programme has been completed.
\end{abstract}

Key words: Traumatic tetraplegia; Retrieval; Multiple level cervical spine fractures.

In the opening scene of the Australian film 'Sunday Too Far Away' the principle character, a shearer between jobs, is driving alone at speed, unrestrained, in a car on a gravel road in outback Australia. The vehicle skids and rolls, eventually coming to rest on its roof. Unharmed he gets himself out of the vehicle, brushes off the dust and strolls off down the track. The film is a myth about life in outback Australia; the following case is real.

\section{Case report}

On 6 October 1986 a 26-year-old sportsman was travelling with two companions in a panel van between Cowell in South Australia and Alice Springs in the Northern Territory, a distance of $1500 \mathrm{~km}$. Feeling tired he stopped driving and lay down on a mattress in the rear of the vehicle. One of his companions took over the driving. Whilst travelling at $100 \mathrm{~km}$ per hour on a bitumen road the vehicle swerved to the left, the driver overcorrected and the vehicle left the roadway on the right, rolled side over side and came to rest against a tree. 


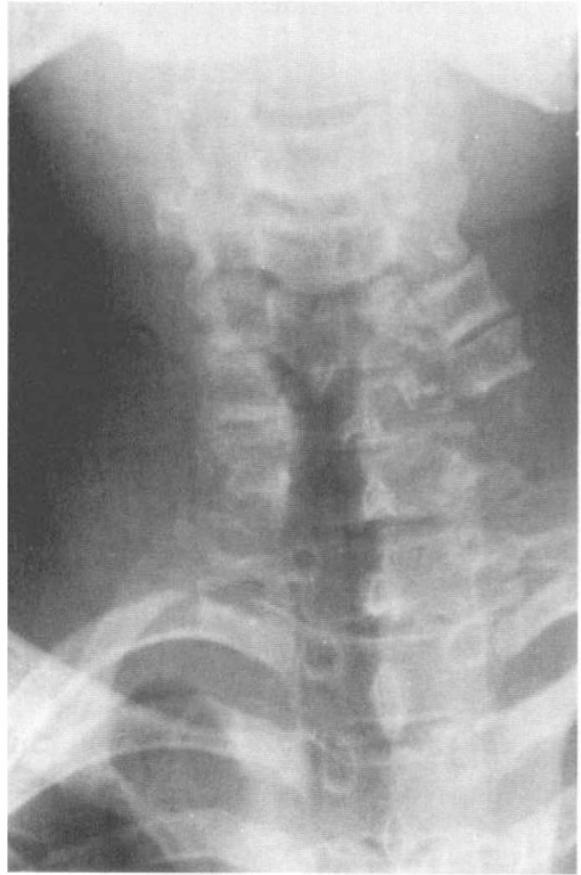

Figure 1 Anteroposterior X-ray of cervical spine on admission

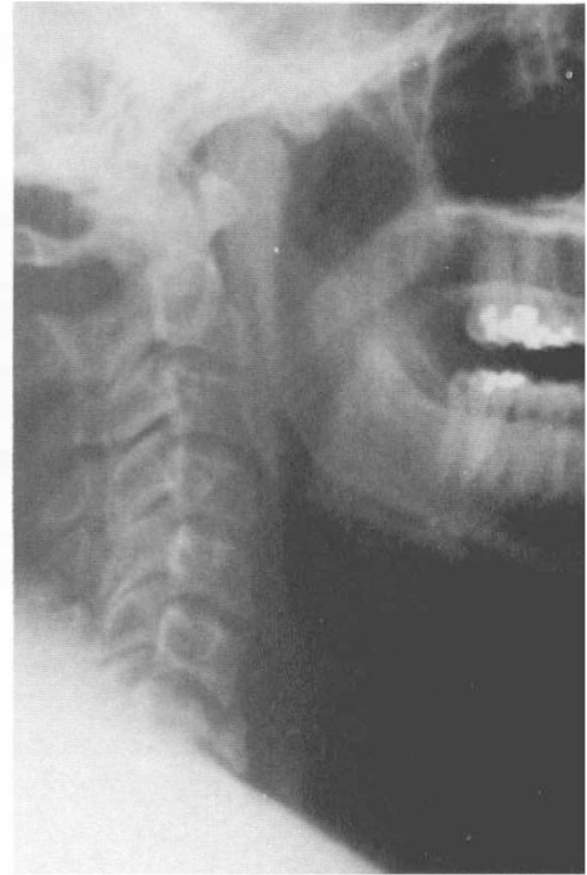

Figure 2 Lateral X-ray of cervical spine on admission

The patent was trapped in the wreckage, unconscious for 1 hour. His companions were unharmed. When a medical officer arrived on the scene 2 hours later he was still trapped in the vehicle. Examination showed that he was conscious and oriented, complaining of severe neck pain. His BP was $90 / 60 \mathrm{~mm} \mathrm{Hg}$ with a bradycardia of 40 per minute. He was unable to move his legs, left arm or right hand. He had lacerations of his occipital scalp. Treatment at the accident scene was appropriate (Yeo, 1979) and included splintage of his cervical spine, oxygen, atropine, IV fluids and analgesia.

Freed from the wreckage 3 hours after injury, he was taken by road ambulance to the nearest airstrip then flown by air ambulance to Alice Springs Hospital. He arrived there 4 hours after the accident. At this stage examination revealed an asymmetrical tetraplegia with a sensory and motor level of $\mathrm{C} 4$ on the left and C6 on the right. Radiographs of the cervical spine showed fractures of the left lateral masses of $\mathrm{C} 5, \mathrm{C} 6$, and $\mathrm{C} 7$, and a burst fracture of $\mathrm{C} 7$ (Fig. 1, Fig. 2). He was nursed in a neutral position with a rigid cervical collar in place and was catheterised.

The patient was admitted to the Spinal Unit of the Royal Adelaide Hospital 27 hours after injury. The neurological findings were unchanged. Skull films and CT head scan were normal. A CT scan of levels C4 to T1 of the cervical spine showed a fracture of the left pedicle of $\mathrm{C} 5$ and both sides of its lamina. There was a comminuted fracture of the left pedicle of C6 involving the lateral mass which was rotated outward as was that of $\mathrm{C} 5$. Both laminae of $\mathrm{C} 6$ were also fractured. There was a comminuted fracture of the body of $\mathrm{C} 7$, with bony fragments visible anteriorly, anterior subluxation of $\mathrm{C} 6$ on $\mathrm{C} 7$, a fracture of the right lamina of $\mathrm{C} 7$ and a comminuted fracture of the anterior part of the $\mathrm{T} 1$ vertebral body. There was some narrowing of the spinal canal at the $\mathrm{C} 6$ level where the left lamina intruded, and at the $\mathrm{C} 7$ level where vertebral body fracture fragments had shifted posteriorly.

Gardner Wells tongs were applied with $5 \mathrm{lb}$ traction. Whilst in traction his neurological state improved from a level of $\mathrm{C} 4$ to a level of $\mathrm{C} 5$ on the left. This was thought to be due to left $\mathrm{C} 5$ root recovery. After 6 weeks in traction he was transferred to the Spinal Injuries Rehabilitation Unit. 
Medical complications during his rehabilitation programme included prolonged bladder atony; possibly due to bladder distension caused by delay in initial catheterisation. He had multiple urinary tract infections whilst catheterised and one episode of epididimo-orchitis.

He was discharged on 21 August 1987 to a shared house with attendant care.

\section{Discussion}

In central Australia the combination of high vehicle speed, straight roads with soft edges and unvaried terrain sets the scene for motor vehicle accidents. Distance from specialist centres for the management of neurotrauma can effect outcome (Simpson et al., 1984). When travelling long distances people often lie down to rest in the rear of their vehicles whilst someone else continues to drive. There are no provisions for restraint of the resting occupant in this situation. Of 10 patients transferred from remote areas of the Northern Territory to our unit with spinal cord injuries resulting from motor vehicle accidents between 1 January 1982 and 1 January 1988, 5 were resting unrestrained in the rear of the vehicle. Of these 3 were recumbent.

The pattern of multiple level cervical vertebral fractures sustained in this case is unusual and illustrates the intense force brought to bear on the cervical spine in this accident. For passengers in the sitting position it is accepted that seat belts reduce the incidence and severity of injury in motor vehicle accidents (Gikas, 1983). It is unknown whether restraints would reduce the injury sustained by recumbent passengers. Also unknown is whether it is more dangerous to rest sideways as opposed to lengthwise in a moving vehicle.

The position of recumbent passengers, nature of the accident and injuries sustained should be studied for inter-relationships before firm recommendations can be made on the question of restraints for recumbent passengers. Meanwhile a safe approach would be to suggest that passengers do not lie recumbent in vehicles. If a rest is needed then both the driver and the passengers should rest and not merely switch roles.

\section{References}

GIKAS PW 1983 Forensic aspects of the highway crash. Pathology Annual 18:147-163.

Simpson D, et al. 1984 Neurological injuries in South Australia: The influence of distance on management and outcome. Australian $\mathcal{E}$ New Zealand fournal of Surgery 54:29-35.

YEO J 1979 First-aid management of spinal cord injuries. The Medical fournal of Australia Nov 17. 